\title{
A relação entre metáforas conceptuais e funções executivas: uma revisão da literatura
}

\section{Conceptual metaphors and executive functions: a review} \\ Johanna Dagort Billig \\ Aline Aver Vanin² \\ Gabriela Peretti Wagner ${ }^{3}$ \\ 1,2 Fundação Universidade Federal de Ciências da Saúde de Porto Alegre, Departamento de Educação e Humanidades. Porto Alegre, RS, Brasil.
3Fundação Universidade Federal de Ciências da Saúde de Porto Alegre, Departamento de Psicologia. Porto Alegre, RS, Brasil.
}

'Doutora em Linguística Aplicada (UFRGS) Professora adjunta do Departamento de Educaçấo e Humanidades da Universidade Federal de Pesquisa o impacto de experiência bilíngue de linguagem na cognição geral. Além disso, estuda o impacto do envelhecimento na linguagem, mais especificamente nas funçöes executivas. (i) https://orcid.org/0000-0002-5435-7

E-mail: johannadb@ufcspa.edu.br

Doutora em Linguística (PUCRS). Professora adjunta do Departamento de Educação e da Saúde de Porto Alegre (UFCSPA). Pesquisa a relação entre metatoras e o discurso sobre 0 câncer de mama, bem como a de metáforas conceptuais e funçoes executivas. (i) https://orcid.org/0000-0003- 1250-3759

E-mail:alinevanin@ufcspa.edu.br

Doutora em Psicologia (UFRGS). Professora adjunta do Departamento de Psicologia da de Porto Alegre (UFCSPA). Atua nas áreas de Neuropsicologia e de Aval aça Neuropsicologica. Integra o Programa de Pós-Graduação em Psicologia e Saúde na mesma instituição. Entps://orcid.org/0000-0003-4260-6847
Resumo: Este artigo de revisão integrativa da literatura busca avaliar as evidências recentes acerca da relação entre o desempenho em tarefas ligadas a funções executivas e a compreensão e a produção de metáforas conceptuais. Para tanto, os descritores "metáforas" e "funções executivas", bem como termos relacionados a este último, foram pesquisados nas bases de dados Pubmed, Scielo e Lilacs. Após seguir critérios de inclusão e de exclusão, foram selecionados sete artigos que trazem debates recentes acerca do tema. A partir dos experimentos descritos nos estudos revisados, verificou-se que há relação entre desempenho em termos de memória de trabalho e de controle inibitório e a compreensão e a produção de metáforas. Ainda, os fatores idade, tamanho de vocabulário e grau de familiaridade com as metáforas são aspectos que modularam as relações entre funcionamento executivo e a compreensão e/ou produção de metáforas.

Palavras-chave: Metáforas conceptuais; Funções executivas; Envelhecimento.

Abstract: This paper, which consists of an integrative literature review, aims at evaluating recent evidence about the relationship between performance in tasks involving executive functions and the understanding and production of conceptual metaphors. The descriptors "metaphors" and "executive functions", as well as terms related to the latter, were searched in Pubmed, Scielo and Lilacs databases. After following inclusion and exclusion criteria, seven papers with recent debates about the theme were selected. From the experiments described in the reviewed studies, it is possible to conclude that there is a relationship between performance in terms of working memory and inhibitory control and the understanding and production of metaphors. Also, aspects such as age, vocabulary size and degree of familiarity with metaphors are aspects that have modulated the relations between executive functioning and the understanding and/or production of metaphors.

Keywords: Conceptual metaphors; Executive functions; Aging. 


\section{Introdução}

uando Lakoff e Johnson escreveram Metaphors we live by, em 1980, e trouxeram para o centro do debate o papel da experiência humana para a linguagem, bem como sobre o seu entendimento acerca do que seria o significado, a Linguística Cognitiva dava os seus primeiros passos. Na época, evidências linguísticas que demonstravam a emergência de metáforas como indícios do que se passa em nível conceptual eram demonstradas em análises de sentenças isoladas, e, embora bastante plausíveis, ainda estavam deslocadas do continuum das interações humanas.

Aplicações empíricas têm sido pensadas e incorporadas ao referencial teórico a fim de avançar em um campo em que, até há muito pouco tempo, se confiava na própria introspecção, como linguistas e falantes da língua, para validar as hipóteses levantadas. Pesquisadores como Gibbs $(2006 ; 2007)$ há alguns anos vêm advogando por uma abordagem mais empírica nos estudos relacionados a áreas da linguística cognitiva e das neurociências no intuito de buscar evidências para fenômenos como os da emergência de metáforas conceptuais e sua relação com, por exemplo, aspectos como aquisição, déficits, compreensão e produção de linguagem.

Este artigo tem por objetivo revisar a literatura recente acerca da relação entre a compreensão e a produção de metáforas conceptuais e o desempenho em tarefas que envolvam funções executivas. Busca-se verificar a existência de estudos empíricos que demonstrem evidências comportamentais acerca dessa relação. O caminho percorrido neste texto perpassará os conceitos principais abordados, a seção de metodologia e, por último, a discussão dos resultados.

\section{Metáforas da vida cotidiana}

Compreender como organizamos a própria experiência e como a elaboramos de forma a traduzi-la em palavras tem sido um dos focos de áreas como a Psicologia, a Linguística e as Neurociências em geral. Um dos principais meios de expressão dos significados que damos às interações na vida cotidiana ocorre por meio da linguagem figurada. A concretização da experiência por meio de metáforas e de metonímias é um indício do modo como nos apropriamos do mundo ao nosso redor: é por meio do mapeamento entre domínios conceptuais do conhecimento que passamos a expressar nosso entendimento em relação ao que vivenciamos. Nesse sentido, falar sobre uma dificuldade em termos de algo que bloqueia um caminho, como em "há uma pedra no meio do caminho" demonstra um entendimento sobre como elaboramos a própria vida em dado momento: se a vida é uma viagem, um problema poderia ser elaborado como obstáculo no meio da viagem/caminho.

Kövecses (2002) afirma que a linguagem metafórica “[...] é a principal forma na qual o sistema cognitivo humano produz a realidade não física, isto é, a realidade social, política, psicológica, emocional, etc." (p. 111). Nesse sentido, quando se diz que alguém se sente "fervendo por dentro", a metáfora raiva é um fluido quente em um recipiente é expressa linguisticamente, demonstrando uma das possibilidades de se pensar sobre essa emoção. Desse modo, podemos dizer que a forma como nos expressamos reflete a maneira como construímos nosso próprio mundo: por isso, o papel e o significado da metáfora é que ela cria certo modelo para determinado conceito (KÖVECSES, 2002). Então, dados construtos conceptuais são denunciados pelo falar: no exemplo, a construção do conceito de raiva é desencadeada conforme o mapeamento entre domínios conceptuais da experiência. 
Para Lakoff e Johnson (1999), a metáfora conceptual funciona como uma ferramenta cognitiva para a elaboração e expressão da experiência humana. O uso de metáforas conceptuais é inerente à comunicação cotidiana, e tal aspecto é indício da forma como a cognição humana interpreta o mundo. 0 modelo proposto por Lakoff e Johnson $(1980 ; 1999)$ coloca a experiência humana no centro do ato cognitivo, apresentando-o como essencialmente dependente da metáfora conceptual. A questão da sistematização da estrutura conceptual humana é referida por Lakoff e Johnson (1980), para os quais a metáfora é uma operação cognitiva fundamental, sendo uma forma de expressão linguística que permeia a fala cotidiana (p. 3).

$\mathrm{Na}$ investigação sobre a ocorrência da metáfora conceptual, Lakoff e Johnson (1980) partem de duas teses fundamentais: (i) os conceitos abstratos são amplamente metafóricos, ou seja, o que não faz parte da realidade concreta é contextualizado na realidade física através de domínios da experiência física; (ii) a mente é essencialmente corpórea, o que significa dizer que os conceitos derivam da experiência sensório-motora. Eles estruturam o que é percebido, como se lida com o mundo e como um indivíduo se relaciona com outras pessoas. Essas construções conceptuais influenciam as experiências e ações individuais e, ao se estabelecerem na cognição, servirão de base para futuras aplicações linguísticas durante a comunicação.

Para Lakoff (1987), o sistema conceptual humano é produto da experiência humana, e esta experiência ocorre por meio do corpo. Não haveria conexão direta entre a linguagem humana e o mundo se ele existisse fora da experiência humana. A linguagem humana está baseada em conceitos humanos, que são, por seu turno, motivados pela experiência humana. Nesse sentido, nossa percepção de mundo está condicionada às construções que fazemos a partir das interações corpóreas dos nossos corpos com os dos que interagimos.
Ao se pensar no processamento cognitivo dessa metáfora, faz-se necessário estabelecer um diálogo com áreas como a da neurociência, haja vista que há indícios que a elaboração de metáforas e de metonímias, sejam elas cristalizadas (isto é, aquelas cuja significação emerge naturalmente, sem qualquer esforço cognitivo para sua interpretação, como em ter um problema é ter uma pedra no caminho) ou criativas ${ }^{1}$ (cuja interpretação requer maior esforço, como ter a mesma ideia é fazer um bluetooth), estão ligadas a determinadas funções executivas, a serem investigadas neste projeto. A próxima seção visa a esclarecer tal conceito.

\section{Funções executivas e metáforas}

Especificamente no que se refere às funções executivas, o termo vem sendo utilizado para descrever uma série de processos cognitivos envolvidos em atividades como "resolução de problemas", "planejamento", "iniciação de atividades" e "memória prospectiva", permitindo o comportamento dirigido a metas (goal directed behavior) (BURGESS, 1997; STUSS; BENSON, 1986; STUSS; LEVINE, 2002). Historicamente, esses processos estão ligados aos lobos frontais do encéfalo (STUSS; BENSON, 1986), mais especificamente às áreas pré-frontais (FUSTER, 1997; STUSS; LEVINE, 2002).

As funções executivas são entendidas como processos mentais elaborados, cujo ápice de desenvolvimento se dá no ser humano (FUSTER, 1997; PASSINGHAM, 1997; TONIETTO et al., 2011). Essas funções, que podem ser definidas de diversas formas, recrutam e se apoiam nas demais funções mentais superiores (linguagem, memória, percepção etc.) (JURADO; ROSSELI, 2007; LURIA, 1966).

${ }^{1} 0$ conceito de criatividade aplica-se a determinado espaço e a tempo específico: tais metáforas acabam envelhecendo e tornando-se cristalizadas com o tempo ou, em um caminho inverso, podem tender desaparecer. 
Existe uma diversidade em termos de modelos teóricos e de componentes envolvidos nas funções executivas (GRAFMAN, 1995; JURADO; ROSSELI, 2007; STUSS; ALEXANDER, 2000), mas a maioria das concepções teóricas abrange alguns componentes ou atividades executivas já descritas por Smith e Jonides (1999). Estes autores afirmam que as funções executivas podem incluir: (i) focar a atenção em informações relevantes e inibir as irrelevantes; (ii) direcionar os processos para o desempenho de tarefas complexas, o que requer o controle da atenção focada para as tarefas em questão; (iii) planejar uma sequência de sub-tarefas para atingir determinado objetivo; (iv) atualizar e monitorar, através da memória de trabalho, as etapas em andamento para determinar o próximo passo numa tarefa sequencial; e (v) codificar as representações na memória de trabalho de acordo com o espaço e o tempo (SMITH; JONIDES, 1999). Essas etapas, com algumas variações, podem ser observadas no modelo do Sistema Atencional de Supervisão (SAS, de NORMAN; SHALLICE, 1986), bem como na concepção de memória de trabalho de Baddeley (BADDELEY; HITCH, 1974; BADDELEY; HITCH, 1994; BADDELEY, 2000), entre outros (CHAN et al., 2008; JURADO; ROSSELI, 2007; MIYAKE et al., 2000). Mais recentemente, esses componentes foram reduzidos a três fatores (MIYAKE et al, 2000): updating (atualização e monitoramento de representações mentais online), shifting (seleção e alternância de processos mentais) e inhibiting (inibição de respostas automáticas). Desta forma, observa-se que nas diversas atividades mentais, mais de um componente executivo pode ser requisitado (CHAN et al., 2008).

Fedorenko (2014) salienta que a linguagem não é um processo isolado de mecanismos cognitivos gerais, e por isso não atuaria isolada de funções sensoriais, de memória, de atenção e de cognição social, por exemplo. Na verdade, diante das amplas possibilidades de comunicação, faz-se necessário um mecanismo cognitivo que possa contribuir para lidarmos com possíveis ambiguidades, interferências de informações não relevantes e para que pos- samos executar nossas ações de comunicação de acordo com nossos objetivos internos. Entre as situações de uso da linguagem que exigem que lidemos com as demandas acima citadas, temos situações de comunicação bilíngue/ multilíngue, situações em que o ouvinte se depara com enunciados implausíveis e situações de compreensão e produção de metáforas, por exemplo.

Falantes bilíngues e multilíngues precisam determinar que língua deve ser usada no momento e evitar a produção de palavras da língua não relevante. Se um ouvinte se depara com um enunciado que lhe parece implausível, ele/a precisa decidir se confia no que acabou de ouvir ou se confia no seu conhecimento de mundo (YE; ZHOU, 2009). Já a compreensão de metáforas (por exemplo, "Minha boca é um túmulo"), conforme Gernsbacher et al. (2001), envolveria a supressão de informações não relevantes ativadas pelo estímulo (túmulo é mal cheiroso) e a seleção de informações relevantes para a interpretação da metáfora (nada sai de dentro do túmulo, nem uma palavra). Evidências (SHAPIRO; MOO; CARAMAZZA, 2006; ROELOFS; PIAI, 2011; STRIJKERS et al., 2011) sugerem que o mecanismo cognitivo que estaria envolvido nos fenômenos descritos acima e em outras situações de seleção de alternativas competidoras, inibição de respostas e/ou interpretações não apropriadas seria o mecanismo de funcionamento executivo.

Mais especificamente, com relação à produção de metáforas, Beaty e Silvia (2013) acreditam que os mecanismos cognitivos exigidos na produção de metáforas convencionais sejam diferentes dos mecanismos cognitivos exigidos na produção de metáforas criativas ou não familiares. De acordo com os pesquisadores, enquanto a produção de metáforas convencionais seria feita de maneira automática e estaria associada ao conhecimento de vocabulário do falante, a produção de metáforas criativas estaria fortemente associada à inteligência fluída e à fluência verbal. Logo, a compreensão e produção de metáforas criativas poderia estar relacionada ao funcionamento executivo. 
Considerando então a possibilidade de que a compreensão e produção de metáforas criativas façam exigências de mecanismos diferentes dos utilizados para a compreensão e produção de metáforas convencionais, podemos esperar que essas habilidades sigam um curso diferente ao longo do desenvolvimento humano, mas especificamente no envelhecimento. Uma vez que a compreensão e produção de metáforas dependeriam mais do tamanho de vocabulário e do conhecimento representacional do indivíduo, que não costumam ser afetados pelo envelhecimento (STUART-HAMILTON, 2002; SALTHOUSE, 2004; VERHAEGHEN, 2003), poderíamos esperar uma ausência de diferenças em termos de desempenho entre adultos e idosos. Por outro lado, se a compreensão e produção de metáforas criativas fazem exigências de mecanismos executivos, então podemos esperar que essas habilidades sejam afetadas pelo envelhecimento. Conforme Zelazo, Craik e Booth (2004), existem evidências de que o funcionamento executivo siga uma curva em forma de U invertido. Ou seja, existe um crescente em termos de funcionamento executivo ao longo da infância e adolescência, mas uma queda nesse funcionamento no envelhecimento.

Na próxima seção, será detalhada a metodologia utilizada para a busca de trabalhos recentes sobre a relação de metáforas conceptuais e de funções executivas.

\section{Metodologia}

A presente revisão integrativa de literatura teve como objetivo responder a seguinte pergunta norteadora: Existem evidências comportamentais de uma relação entre o desempenho em tarefas de funções executivas e o desempenho em termos de compreensão e produção de metáforas? A partir dessa pergunta de pesquisa, foram feitas buscas nas bases de dados Pubmed, Scielo e Lilacs, entre julho e agosto de 2017, com base nos descritores "metáforas" e "funções executivas". Como o descritor "funções executivas" é um termo guarda-chuva para um conjunto de componentes cognitivos superiores (por exemplo, controle inibitório e memória de trabalho, planejamento), também foram feitas buscas cruzando o descritor "metáforas" com os descritores "memória de trabalho" e "controle inibitório". o Quadro 1 apresenta o número de artigos encontrados para as buscas com cada combinação de descritor. Consideraram-se artigos publicados nas línguas portuguesa, espanhola e inglesa.

Quadro 1 - Sistematização da busca eletrônica entre julho e agosto de 2017

\begin{tabular}{|l|l|c|c|}
\hline $\begin{array}{l}\text { Banco de } \\
\text { dados }\end{array}$ & Descritores & $\begin{array}{c}\text { Artigos } \\
\text { encontrados } \\
\text { n }\end{array}$ & $\begin{array}{c}\text { Artigos } \\
\text { pré-selecionados } \\
\text { n }\end{array}$ \\
\hline Pubmed & "Metáforas" e "funções executivas" & 13 & 2 \\
\hline Pubmed & "Metáforas" e "memória de trabalho" & 29 & 6 \\
\hline Pubmed & "Metáforas e "controle inibitório" & 2 & 0 \\
\hline Scielo & "Metáforas" e "funções executivas" & 0 & 0 \\
\hline Scielo & "Metáforas" e "memória de trabalho" & 7 & 0 \\
\hline Scielo & "Metáforas e "controle inibitório" & 0 & 0 \\
\hline Lilacs & "Metáforas" e "funções executivas" & 18 & 3 \\
\hline Lilacs & "Metáforas" e "memória de trabalho" & 30 & 9 \\
\hline Lilacs & "Metáforas" e "controle inibitório" & 4 & 0 \\
\hline
\end{tabular}

Foram adotados os seguintes critérios de inclusão: estudos realizados com jovens adultos e idosos; estudos com populações saudáveis; estudos em que foram investigados a compreensão e/ou produção de metáforas em relação ao desempenho dos participantes em termos de funcionamento executivo. Foram excluídos da amostra: estudos de neuroimagem; estudos com crianças ou com populações não saudáveis e estudos que não investigaram o desempenho dos participantes em termos de compreensão 
e/ou produção de metáforas em comparação com o desempenho dos participantes em termos de funcionamento executivo.

Além dos artigos selecionados pelas buscas nas bases de dados, que após a exclusão de artigos repetidos ficaram em número de quatro (4), fizemos a busca e leitura de outros três (3) artigos que foram mencionados nas referências dos artigos selecionados, pois eles apresentaram potencial para responder a nossa pergunta de pesquisa.

\section{Resultados e discussão}

O Quadro 2 apresenta os artigos selecionados para esta revisão com autores e ano de publicação, objetivos, instrumentos de pesquisa e achados principais. Foram sete artigos selecionados no final, quatro através das buscas nas três bases de dado e três que foram encontrados após análise das referências dos artigos encontrados.

Quadro 2 - Artigos incluídos na revisão

\begin{tabular}{|c|c|c|c|}
\hline Autores e ano de publicação & Objetivos & Instrumentos de pesquisa & Principais achados \\
\hline Kazmerski, Blasko e Dessalegn (2003) & $\begin{array}{l}\text { Investigar o impacto de diferenças individuais na } \\
\text { compreensão de metáforas. }\end{array}$ & $\begin{array}{l}\text { Experimento 1: } \\
\text { Não será discutido aqui, pois envolveu imageamento } \\
\text { cerebral. } \\
\text { Experimento 2: } \\
\text { MAB (QI) } \\
\text { Span auditivo de palavras em sentenças } \\
\text { Span visuoespacial }\end{array}$ & $\begin{array}{l}\text { - } \\
\text { Houve uma relação entre o desempenho dos participantes } \\
\text { no teste de QI e na tarefa de memória de trabalho verbal e } \\
\text { o teste de compreensão de metáforas. Não houve relação } \\
\text { entre o desempenho dos participantes em termos de } \\
\text { memória de trabalho espacial e o teste de compreensão de } \\
\text { metáforas. }\end{array}$ \\
\hline Chiappe, Chiappe (2007) & $\begin{array}{l}\text { Investigar a hipótese de que diferenças } \\
\text { individuais em termos de memória de trabalho e } \\
\text { controle inibitório podem afetar a compreensão } \\
\text { (Exp. 1) e produção de metáforas (Exp. 2). }\end{array}$ & $\begin{array}{l}\text { Experimento 1: } \\
\text { Compreensão de metáforas ( } \mathrm{n}=48 \text { ), Span auditivo de } \\
\text { palavras em sentenças, Tarefa de Stroop } \\
\text { Experimento 2: } \\
\text { Span auditivo de palavras em sentenças; tarefa de } \\
\text { fluência verbal (alimentos e bebidas; nomes de } \\
\text { pessoas; animais); Tarefa de Geração de Metáforas; } \\
\text { Teste Peabody } \\
\text { Experimento 3: } \\
\text { Span auditivo de palavras em sentenças; tarefa de } \\
\text { fluência verbal (alimentos e bebidas; nomes de } \\
\text { pessoas; animais); Tarefa de Geração de Metáforas; } \\
\text { Span de Dígitos ordem direta e na ordem indireta; } \\
\text { Magazine Recognition Questionnaire (exposição a } \\
\text { leitura) }\end{array}$ & $\begin{array}{l}\text { Experimento 1: } \\
\text { A capacidade de memória de trabalho e de controle } \\
\text { inibitório foi capaz de prever o tempo necessário } \\
\text { para interpretar as metáforas e a qualidade dessas } \\
\text { interpretações. } \\
\text { Experimento 2: } \\
\text { A qualidade de produção de metáforas correlacionou-se } \\
\text { com o desempenho dos participantes nas tarefas de } \\
\text { fluência verbal, de span de palavras e de Peabody. } \\
\\
\text { Experimento 3: } \\
\text { O desempenho dos participantes em termos de geração } \\
\text { de metáforas foi relacionado ao desempenho dos } \\
\text { participantes em todas as medidas em graus diferentes, } \\
\text { à exceção do desempenho na tarefa de span de dígitos } \\
\text { (ordem direta). O conhecimento verbal cristalizado parece } \\
\text { ter um papel superior ao da memória de trabalho na } \\
\text { produção de metáforas. }\end{array}$ \\
\hline
\end{tabular}


Quadro 2 (continuação)

\begin{tabular}{|c|c|c|c|}
\hline Autores e ano de publicação & Objetivos & Instrumentos de pesquisa & Principais achados \\
\hline Pierce, MacLaren, Chiappe (2010) & $\begin{array}{l}\text { Investigar o papel da memória de trabalho e do } \\
\text { tamanho de vocabulário na compreensão de } \\
\text { metáforas. }\end{array}$ & $\begin{array}{l}\text { Span de palavras } \\
\text { Tarefa de Julgamento de frases } \\
\text { Teste de vocabulário receptivo (PPVT III) }\end{array}$ & $\begin{array}{l}\text { Quando controlado o efeito de tamanho de vocabulário, } \\
\text { os participantes com maior capacidade de memória de } \\
\text { trabalho foram mais rápidos para julgar as sentenças. }\end{array}$ \\
\hline Morrone et al. (2010) & $\begin{array}{l}\text { Testar a hipótese de que existe um declínio das } \\
\text { capacidades inibitórias relacionado à idade. }\end{array}$ & $\begin{array}{l}\text { Tarefa de julgamento de frases } \\
\text { (literais x metafóricas x anômalas) } \\
\text { Tarefa Hayling } \\
\text { Tarefa Stroop } \\
\text { Span de dígitos -ordem direta e indireta (WAIS-III) } \\
\text { Sequência de números e Letras } \\
\text { (WAIS-III) }\end{array}$ & $\begin{array}{l}\text { Para os adultos jovens, nenhum dos testes psicométricos } \\
\text { previu o tempo de decisão da tarefa de julgamento das } \\
\text { frases, nem o número de erros. Porém, entre os adultos } \\
\text { idosos, o tempo de decisão para rejeitar frases contendo } \\
\text { metáforas foi previsto pelo tempo de reação da tarefa } \\
\text { de Hayling e pelo tempo de reação na tarefa Stroop. } \\
\text { O número de erros dos idosos na tarefa de julgamento } \\
\text { também foi previsto pelo efeito Stroop. }\end{array}$ \\
\hline Mashal (2013) & $\begin{array}{l}\text { Examinar as relações entre memória de trabalho } \\
\text { e a compreensão e a recuperação de metáforas } \\
\text { familiares e não familiares. }\end{array}$ & $\begin{array}{l}\text { Experimento 1: } \\
\text { Span de dígitos- ordem direta e indireta (WAIS-III) } \\
\text { Tarefa de Compreensão de metáforas } \\
\text { Experimento 2a: } \\
\text { Span de dígitos- ordem direta e indireta (WAIS-III) } \\
\text { Tarefa de Reconhecimento de Metáforas (5 pares) } \\
\text { Experimento 2b: } \\
\text { Span de dígitos- ordem direta e indireta (WAIS-III) } \\
\text { Tarefa de Reconhecimento de Metáforas (5 pares) } \\
\text { Experimento 3: } \\
\text { Span de dígitos- ordem direta e indireta (WAIS-III) } \\
\text { Tarefa de recuperação de metáforas }\end{array}$ & $\begin{array}{l}\text { A memória de trabalho parece estar envolvida na } \\
\text { compreensão e recuperação de metáforas familiares } \\
\text { e não familiares. Entretanto, através da análise dos } \\
\text { erros cometidos, foi possível observar que diferentes } \\
\text { componentes da memória de trabalho estão envolvidos } \\
\text { na compreensão e recuperação de cada um dos tipos de } \\
\text { metáforas. O componente executivo parece facilitar o } \\
\text { processamento de metáforas não familiares, enquanto } \\
\text { que a alça fonológica parece ter um papel mais importante } \\
\text { no processamento de metáforas familiares. }\end{array}$ \\
\hline Iskandar, Baird (2014) & $\begin{array}{l}\text { Investigar se a interpretação de metáforas } \\
\text { mais acurada estava mais associada à memória } \\
\text { de curto prazo, à memória de trabalho ou à } \\
\text { atenção dividida. }\end{array}$ & $\begin{array}{l}\text { Teste de Interpretação de Metáforas } \\
\text { Span de dígitos (ordem direta e indireta) } \\
\text { Teste de repetição de sentença } \\
\text { Teste do Trigrama de Consoantes }\end{array}$ & $\begin{array}{l}\text { O desempenho dos participantes em termos de memória } \\
\text { de curto prazo foi mais preditivo de interpretações mais } \\
\text { acuradas de metáforas do que o desempenho em termos } \\
\text { de memória de trabalho e de atenção dividida. }\end{array}$ \\
\hline Columbus et al. (2015) & $\begin{array}{l}\text { Investigar se diferenças individuais em termos } \\
\text { de controle executivo estão relacionadas ao } \\
\text { processamento de metáforas. }\end{array}$ & $\begin{array}{l}\text { Tarefa AX-CPT (funções executivas) } \\
\text { Rastreamento ocular } \\
\text { da leitura de metáforas e expressões idiomáticas }\end{array}$ & $\begin{array}{l}\text { Familiaridade modulava o tempo gasto para a primeira } \\
\text { leitura. } \\
\text { Leitores com maior controle cognitivo gastavam } \\
\text { mais tempo fixando na leitura do verbo (com sentido } \\
\text { metafórico) na primeira leitura. Porém, os leitores } \\
\text { com baixo controle cognitivo, demonstravam mais } \\
\text { dificuldade na leitura, pois apresentavam mais tempo } \\
\text { de leitura totais e uma maior probabilidade de } \\
\text { reler a frase. }\end{array}$ \\
\hline
\end{tabular}


Nosso objetivo com esta revisão foi investigar se há evidências cognitivas e comportamentais de uma relação entre o desempenho em tarefas de funções executivas e o desempenho em termos de compreensão e de produção de metáforas. Após a leitura dos sete artigos selecionados, acreditamos ser importante destacar quatro achados relevantes e cinco limitações que apontam necessidades de estudos futuros.

O primeiro achado destacado são as relações entre desempenho em termos de memória de trabalho e de controle inibitório e a compreensão e a produção de metáforas. Seis dos sete artigos selecionados encontraram relações entre o desempenho de memória de trabalho e a compreensão e/ou produção de metáforas. Esses estudos fizeram uso de diferentes tarefas para a avaliação de memória de trabalho, e é importante destacar que as relações entre memória de trabalho e compreensão e produção de metáforas foram mais proeminentes quando as tarefas utilizadas para avaliar memória de trabalho faziam mais exigências do componente executivo da memória de trabalho (por exemplo, span de dígitos na ordem indireta). Park e Payer (2006) chamam a atenção para o fato de que a memória de trabalho envolve tanto aspectos de armazenamento quando de processamento (manipulação e transformação) das informações. Dessa forma, segundo os autores, tarefas que exijam a simples repetição de uma lista de palavras e/ou números, por exemplo, são medidas de memória de curto prazo e não de memória de trabalho. Também não foram encontradas evidências de uma relação da memória de trabalho com a compreensão de metáforas, quando a tarefa utilizada para avaliar memória de trabalho envolveu uma tarefa não verbal.

Dos cinco estudos que avaliaram a relação entre controle inibitório e a compreensão e/ou produção de metáforas, apenas um não encontrou evidências significativas dessa relação. Iskandar e Baird (2014) encontraram relações significativas apenas entre o desempenho em termos de memória de curto prazo e a compreensão de metáforas, mas não entre o desempenho em termos de memória de trabalho e/ou atenção dividida e a compreensão de metáforas. Para os autores, essa evidência fornece suporte a modelos computacionais de compreensão de linguagem figurada, que preveem a necessidade de se armazenar as expressões metafóricas por tempo suficiente para fazer as comparações semânticas necessárias para compreensão dessas expressões. Acreditamos que uma possível explicação para a ausência de evidências favoráveis de uma relação entre componentes executivos e a compreensão e/ou produção de metáforas nesse estudo pode estar relacionada a um dos três achados que também destacamos. Esses achados são aspectos que modularam as relações entre funcionamento executivo e a compreensão e/ou produção de metáforas: idade, tamanho de vocabulário e grau de familiaridade das metáforas.

Em seu estudo, Morrone et al. (2010) observaram uma relação entre controle inibitório e compreensão de metáforas apenas entre adultos e idosos. Com base em avaliação de compreensão de metáforas, o experimento demonstrou que participantes mais idosos precisaram de mais tempo para realizar as tarefas e erraram mais vezes ao rejeitar enunciados que continham metáforas em detrimento de frases literalmente falsas.

No único estudo encontrado que investigou produção de metáforas, Chiappe e Chiappe (2007) realizaram uma série de análises estatísticas de comunalidade para discriminar que mecanismos pareciam estar mais ou menos envolvidos no desempenho dos participantes. Nessa análise, os pesquisadores observaram que os escores dos participantes na tarefa de tamanho de vocabulário explicavam $26,6 \%$ da variação de desempenho dos participantes; os escores de exposição à leitura representavam 17,3\% dessa variação e os escores na tarefa de memória de trabalho representavam 20,4\% da variação de desempenho na produção de metáforas. Esse é o terceiro achado que chama a atenção. Não é surpreendente que o tamanho de vocabulário e a exposição à leitura afetem a compreensão leitora, 
mas é importante investigar em que aspectos o tamanho de vocabulário e da exposição à leitura parecem serem fatores mais determinantes para a compreensão e produção de metáforas do que outros aspectos cognitivos.

Uma possível explicação para esse achado pode estar na seleção de metáforas para as tarefas de compreensão; apenas um dos sete artigos selecionados considerou o grau de familiaridade das metáforas apresentadas. Esse é o quarto achado que destacamos. Na maioria dos estudos, não há menção de critérios de seleção de metáforas para as tarefas e, como elas costumam ser feitas a partir de bancos já existentes e não tão recentes (GLUCKSBERG et al., 1982; KATZ et al., 1988), é provável que se tratem de metáforas já familiares, ou cristalizadas, aos participantes.

No único estudo que considerou o grau de familiaridade das metáforas na tarefa de compreensão, Mashal (2013) investigou essa relação por meio de três experimentos. No primeiro, a capacidade de memória de trabalho dos participantes foi avaliada por meio do teste de span de dígitos em ordem direta e inversa (Digit Span WAIS-III) e a compreensão de metáforas foi avaliada por meio de uma tarefa de múltipla escolha. Nessa tarefa, os participantes eram solicitados a escolher a opção correta de interpretação de 30 pares de palavras (10 metáforas familiares, 10 metáforas nãofamiliares e 10 pares de palavras não relacionadas). Os resultados desse experimento revelaram que o desempenho dos participantes na tarefa de span de dígitos de ordem inversa se correlacionou com o desempenho dos participantes tanto na compreensão de metáforas não-familiares, quanto na compreensão de metáforas familiares. No segundo experimento, os participantes também realizaram o teste de span de dígitos na ordem direta e inversa, mas realizaram uma tarefa de compreensão de metáforas diferente. Essa tarefa envolvia ouvir uma lista de pares de palavras (metáforas familiares, metáforas não familiares e pares de palavras não relacionadas) e depois lembrar a palavra que completava cada um dos pares de palavras apresentados. Além da resposta certa, entre as opções havia um distrator fonológico, um distrator semântico, uma opção plausível e uma opção que não era nem fonológica e nem semanticamente relacionada com a primeira palavra. O resultado do experimento revelou: (i) uma correlação positiva entre o desempenho na tarefa de span de dígitos na ordem inversa e o correto reconhecimento das metáforas não familiares; (ii) que os participantes cometiam mais erros fonológicos na recuperação de metáforas familiares, o que sugere um processo mais superficial de manutenção de informação na alça fonológica na recuperação desse tipo de metáfora. 0 último experimento envolvia o mesmo teste de memória de trabalho, mas a tarefa de compreensão de metáforas envolvia a recordação livre de três listas de pares de palavras contendo metáforas familiares, metáforas não familiares e pares de palavras não relacionadas. Nesse experimento, os participantes lembraram significativamente mais de metáforas familiares do que de metáforas não familiares. Esses resultados foram interpretados pelo pesquisador como indicativo do papel da memória de trabalho na compreensão de metáforas não familiares, mas especificamente do papel do executivo central na supressão de informação não relevante.

O fato de as funções executivas estarem mais envolvidas na compreensão de metáforas criativas ou não familiares faz sentido se pensarmos que o grau de envolvimento dos componentes executivos é modulado pelo fator novidade, ou criatividade. Conforme estudo de Diamond (2006), dançarinos inexperientes precisam se concentrar bastante e contar muito com as funções executivas para executar uma dança, mas um dançarino experiente não. Conforme Beaty e Silvia (2013), metáforas convencionais e criativas parecem estar ancoradas em diferentes padrões ou habilidades: enquanto as primeiras emergem de conhecimento do vocabulário, as segundas dependem mais de processos executivos. 
Com relação às limitações da literatura investigada, chamamos a atenção para cinco questões. Em primeiro lugar, está o fato de quatro dos sete estudos terem amostras que variaram entre trinta e sessenta participantes, ou seja, amostras pequenas para generalizarmos os resultados.

Outra limitação levantada é a carência de estudos que analisem as relações entre produção de metáforas e funcionamento executivo. Dos sete estudos analisados, somente um estudo investigou a produção de metáforas. É possível que a falta de tarefas de produção de metáforas validadas seja uma das razões para encontrarmos apenas um único estudo de produção. Além disso, a dificuldade de avaliar a produção de metáforas pode ser outro obstáculo. No estudo de Chiappe e Chiappe (2007), os pesquisadores fizeram uso de dois avaliadores para pontuar de 0 a 5 as metáforas produzidas. A pontuação de zero era atribuída ao participante que não conseguia produzir um veículo para atribuir a propriedade sugerida pelos pesquisadores ao substantivo sugerido. Quanto maior o escore, maior a adequação do veículo utilizado para descrever a propriedade sugerida pelos pesquisadores a um determinado substantivo. Não fica claro, entretanto, o que seria um veículo que merecesse a atribuição de dois (2) pontos ou um veículo que merecesse cinco (5) pontos.

Uma terceira carência dessa área de investigação é a exploração do impacto do envelhecimento na compreensão e produção de metáforas. Apesar do aumento dessa população, não encontramos mais estudos que investigaram efeitos de envelhecimento em adultos saudáveis. A investigação desses efeitos pode gerar a criação de instrumentos que sejam capazes de rastrear de maneira muito mais ecológica o aparecimento de patologias no envelhecimento, já que a compreensão e produção de linguagem metafórica fazem parte do nosso cotidiano.

O quarto aspecto limitador é a ausência de análise do grau de familiaridade das metáforas selecionadas para os estudos. É possível que a falta de estudos que façam essa análise e essa diferenciação esteja relacionada com a inclusão de tarefas já validadas na sua maioria. O que parece ser algo positivo para garantir a qualidade das tarefas selecionadas e a replicação de estudos similares pode também ser um aspecto limitador. Metáforas que hoje podem ser classificadas como não familiares ou criativas podem perder essa característica ao longo dos anos. Por isso, talvez fosse interessante a realização de estudos-piloto para reavaliar, sempre que possível, o grau de familiaridade das metáforas selecionadas. Como mencionado anteriormente, existem evidências de que o nível de familiaridade possa impactar na compreensão e produção de metáforas e de que as funções executivas são mais solicitadas na realização de tarefas novas ou não habituais. Logo, não é possível analisar as relações entre funcionamento executivo e a compreensão e produção de metáforas sem levar em consideração este aspecto.

O último aspecto limitador da literatura analisada é a carência de estudos que considerem variáveis como tamanho de vocabulário e hábitos de leitura. Somente um dos estudos analisados investigou os hábitos de leitura dos participantes e o instrumento utilizado para essa investigação parece pouco representativo das opções de leitura a que a população tem acesso. Chiappe e Chiappe (2007) investigaram a exposição de leitura de seus participantes através do Magazine Recognition Questionnaire, que é um instrumento em que os participantes são avaliados pelo número de títulos de revista que eles reconhecem. Somente dois dos sete estudos analisaram o tamanho de vocabulário receptivo dos participantes e isso foi feito através do Peabody (PPVT III).

\section{Considerações finais}

Esta pesquisa de revisão integrativa teve por objetivo avaliar estudos recentes que investigassem evidências comportamentais de uma 
possível relação entre o desempenho em tarefas de funções executivas e o desempenho em termos de compreensão e produção de metáforas conceptuais. Considerou-se a diferença entre metáforas convencionais, ou cristalizadas, e metáforas criativas, chamando a atenção para a relevância de os instrumentos serem continuamente reavaliados quanto aos aspectos contextuais - no sentido de as metáforas se cristalizarem com o tempo, ou simplesmente deixarem de ser utilizadas e perder seu caráter de novidade.

Encontrou-se, nos experimentos descritos, que parece haver relação entre o desempenho ligado à memória de trabalho e de controle inibitório e a compreensão e produção de metáforas. Dentre outros achados, verificouse que idade, vocabulário e grau de familiaridade com metáforas são fatores que modularam essa relação.

Os trabalhos revisados apresentaram, porém, lacunas no conhecimento sobre as relações entre metáforas e funções executivas, bem como a maioria possui um número de participantes muito baixo para ser possível uma avaliação mais acurada. Além disso, há pouca literatura sobre a relação do impacto do envelhecimento para o reconhecimento e para a produção de metáforas. Por fim, verificou-se que são pouco investigados o grau de familiaridade de metáforas e o impacto do tamanho do vocabulário e os hábitos de leitura tanto para a compreensão quanto para a produção desse aspecto que emerge pela língua.

\section{Referências}

BADDELEY, A. D. The episodic buffer: A new component of working memory? Trends in Cognitive Sciences, v. 4, n. 11, p. 417-423, 2000. https://doi.org/10.1016/S13646613(00)01538-2

BADDELEY, A. D.; HITCH, G. J. Working memory. In: G. BOWER (Ed.). Recent advances in learning and motivation. New York: Academic Press, 1974. p. 47-90. https://doi. org/10.1016/S0079-7421(08)60452-1
BADDELEY, A. D.; HITCH, G. J. Developments in the concept of working memory. Neuropsychology, v. 8, n. 4, p. 485-493, 1994. https://doi.org/10.1037/08944105.8.4.485

BEATY, R.; SILVIA, P. Metaphorically speaking: cognitive abilities and the production of figurative language. Memory and Cognition, v. 41, n. 2, p. 255-267, 2013. https://doi. org/10.3758/s13421-012-0258-5

BURGESS, P. W. Theory and methodology in executive function research. In: P. Rabbit (Ed.), Methodology of frontal and executive function. East Sussex: Psychology Press Publishers, 1997. p. 81-116.

CHAN, R. C. K.; SHUM, D.; TOULOPOULOU, T.; CHEN, E. Y. H. (2008). Assessment of executive functions: Review of instruments and identification of critical issues. Archives of Clinical Neuropsychology, v. 23, n. 2, p. 201-216, 2008. https://doi.org/10.1016/j. acn.2007.08.010

CHIAPPE, D.; CHIAPPE, P. The role of working memory in metaphor production and comprehension. Journal of Memory and Language, v. 56, n. 2, p. 172-188, 2007. https:// doi.org/10.1016/j.jml.2006.11.006

COLUMBUS, G.; SHEIKH, N. A.; CÔTÉ-LECALDARE, M.; HÄUSER, K. BAUM, S. R.; TITONE, D. Individual differences in executive control relate to metaphor processing: an eye movement study of sentence reading. Frontiers in human neuroscience, v. 8, p. 1-12, 2015. https://doi.org/10.3389/fnhum.2014.01057

FEDORENKO, E. The role of domain-general cognitive control in language comprehension. Frontiers in Psychology, v. 5, p. 1-17, 2014. https://doi.org/10.3389/fpsyg.2014.00335

FUSTER, J. The prefrontal cortex: Anatomy, physiology and neuropsychology of the frontal lobe. New York: Raven Press, 1997

GERNSBACHER, M., KEYSAR, B., ROBERTSON, R., WERNER, N. The role of suppression and enhancement in understanding metaphors. Journal of Memory and Language, v. 45, n. 3, p. 433-450, 2001. https://doi.org/10.1006/jmla.2000.2782

GIBBS, R. W. Cognitive linguistics and metaphor research: past successes, skeptical questions, future challenges. DELTA: Documentação de Estudos em Lingüística Teórica e Aplicada, 22 (sp.), p. 1-20, 2006.

GIBBS, R. W. Why Cognitive Linguists Should Care More About Empirical Methods. In GONZALEZ-MARQUEZ, M. et al. (Ed.). Methods in Cognitive Linguistics. Ithaca: John Benjamins, 2007. https://doi.org/10.1075/hcp.18.06gib 
GLUCKSBERG, S.; GILDEA, P.; BOOKIN, H. B. On understanding nonliteral speech: Can people ignore metaphors? Journal of Verbal Learning \& Verbal Behavior, v. 21, n. 1, p. 85-98, 1982. https://doi.org/10.1016/S0022-5371(82)90467-4

GRAFMAN, J. Similarities and distinctions among current models of prefrontal cortical functions. Annals of the New York Academy of Sciences, v. 769, n. 1, p. 337-368, 1995. https://doi.org/10.1111/j.1749-6632.1995.tb38149.x

ISKANDAR, S.; BAIRD, A. D. The Role of Working Memory and Divided Attention in Metaphor Interpretation. Journal of Psycholinguistic Research, v. 43, n. 4, p. 555-568, 2014. https://doi.org/10.1007/s10936-013-9267-1

JURADO, M. B.; ROSSELI, M. The elusive nature of executive functions: A review of our current understanding. Neuropsychology Review, v. 17, n. 3, p. 213-233, 2007. https:// doi.org/10.1007/s11065-007-9040-z

KATZ, A. N.; PAIVIO, A.; MARSCHARK, M.; CLARK, J. M. Norms for 204 literary and 260 nonliterary metaphors on 10 psychological dimensions. Metaphor \& Symbolic Activity, v. 3, n. 4, p. 191-214, 1988

KAZMERSKI, V. A.; BLASKO, D. G.; DESSALEGN, B. G. ERP and behavioral evidence of individual differences in metaphor comprehension. Memory \& Cognition, v. 31, n. 5, p. 673-689, 2003. https://doi.org/10.3758/BF03196107

KÖVECSES, Z. Metaphor: a practical introduction. New York: Oxford University Press, 2002. LAKOFF, G. Women, Fire and Dangerous Things: What Categories Reveal About the Mind. Chicago: University of Chicago Press, 1987. https://doi.org/10.7208/ chicago/9780226471013.001.0001

LAKOFF, G.; JOHNSON, M. Metaphors We Live By. Chicago: The University of Chicago Press, 1980

LAKOFF, G.; JOHNSON, M. Philosophy in the flesh: the embodied mind and its challenge to western thought. New York: Basic Books, 1999.

LURIA, A. R. Higher cortical functions in man. New York: Basic Books, 1966.

MASHAL, N. The role of working memory in the comprehension of unfamiliar and familiar metaphors. Language and Cognition, v. 5, n. 4, p. 409-436, 2013. https://doi. org/10.1515/langcog-2013-0024

MORRONE, I.; DECLERCQ, C.; NOVELLA, J. C.; BESCHE, C. Aging and Inhibition Processes: The Case of Metaphor Treatment. Psychology and Aging. v. 25, n. 3, p. 697-670, 2010. https://doi.org/10.1037/a0019578
MIYAKE, A.; FRIEDMAN, N. P.; EMERSON; M. J.; WITZKI, A. H.; HOWERTER, A.; WAGER, T. D. The Unity and Diversity of Executive Functions and Their Contributions to Complex "Frontal Lobe" Tasks: A Latent Variable Analysis. Cognitive Psychology, v. 41, n. 1, p. 49-100, 2000. https://doi.org/10.1006/cogp.1999.0734

NORMAN, D. A.; SHALLICE, T. Attention to action: willed and automatic control of behaviour. In: DAVIDSON, R. J.; SCHWARTZ, G. E.; SHAPIRO, D. (Eds.). Conscientiousness and self-regulation. New York: Plenum Press, 1986. p. 1-18. https://doi.org/10.1007/9781-4757-0629-1 1

PARK, D. C.; PAYER, D. Working memory across the adult lifespan. In: BIALYSTOK, E.; CRAIK, F. I. M. (eds.) Lifespan cognition: mechanisms of change. Oxford: Nova York, 2006. https://doi.org/10.1093/acprof:oso/9780195169539.003.0009

PASSINGHAM, R. The frontal lobes and voluntary action. Oxford: Oxford University Press, 1997.

PIERCE, R. S.; MACLAREN, R.; CHIAPPE, D. L. The role of working memory in the metaphor interference effect. Psychonomic Bulletin \& Review, v. 17, n. 3, p. 400-404 2010. https://doi.org/10.3758/PBR.17.3.400

ROELOFS, A.; PIAI, V. Attention demands of spoken word planning: a review. Frontiers in Psychology, v. 2, p. 1-14, 2011. https://doi.org/10.3389/fpsyg.2011.00307

SALTHOUSE, T. A. What and when of cognitive aging. Current Directions in Psychological Science, v. 13, n. 4, p. 140-144, 2004. https://doi.org/10.1111/j.0963-7214.2004.00293.x

SHAPIRO, K. A.; MOO, L. R.; CARAMAZZA, A. Cortical signatures of noun and verb production. Proceedings of the National Academy of Sciences, v. 103, n. 5, p. 1644-1649, 2006. https://doi.org/10.1073/pnas.0504142103

SMITH, E. E.; JONIDES, J. Storage and executive processes in the frontal lobes. Science, v. 283, n. 12, p. 1657-1661, 1999. https://doi.org/10.1126/science.283.5408.1657

STUART-HAMILTON, I. A psicologia do envelhecimento: uma introdução. Porto Alegre: Artmed, 2002

STRIJKERS, K.; YUM, Y. N.; GRAINGER, J.; HOLCOMB, P. J. Early goal-directed top down influences in the production of speech. Frontiers in Psychology, v. 2, p. 1-10, 2011. https://doi.org/10.3389/fpsyg.2011.00371

STUSS, D. T.; ALEXANDER, M. P. Executive functions and the frontal lobes: A conceptual view. Psychological Research, v. 63, n. 3-4, p. 289-298, 2000. https://doi.org/10.1007/ s004269900007 
STUSS, D. T.; BENSON, D. F. The frontal lobes. New York: Raven Press, 1986.

STUSS, D. T. LEVINE, B. Adult clinical neuropsychology: Lessons from studies of the frontal lobes. Annual Review of Psychology, v. 53, p. 401-433, 2002. https://doi. org/10.1146/annurev.psych.53.100901.135220

TOnietTo, L.; WAgneR, G. P.; TREnTini, C. M.; SPERB, T. M.; PARENTE, M. A. M. P. Interfaces entre funções executivas, linguagem e intencionalidade. Paidéia, v. 21, n. 49, p. 247-255, 2011. https://doi.org/10.1590/S0103-863X2011000200012

VERHAEGHEN, P. Aging and vocabulary scores: a meta-analysis. Psychology and Aging, v. 18, v. 2, p. 332-339, 2003.

YE, Z.; ZHOU, X. Executive control in language processing. Neuroscience and Biobehavioral Reviews, v. 33, n. 8, p. 1168-1177, 2009. https://doi.org/10.1016/j. neubiorev.2009.03.003

ZELAZO, P.; CRAIK, F.; BOOTH, C. Executive function across the lifespan. Acta Psychologica, v. 115, n. 2-3, 167-183, 2004. https://doi.org/10.1016/j.actpsy.2003.12.005

Recebido em 15/11/2017

Aceito em 21/02/2018 